\title{
Establishing a postgraduate fellowship in humanitarian medicine - building capacity and ensuring sustainability for the health sector in the Rohingya Crisis
}

\author{
Mir Saaduddin Ahmad ${ }^{\mathrm{a} *}$ and Kay Mohanna ${ }^{\mathrm{b}}$ \\ ${ }^{a}$ Academic Medicine, Dr Nizam Medical Centre, Dhaka, Bangladesh; ${ }^{b}$ College of \\ Health, Life and Environmental Science, University of Worcester, Worcester, UK \\ *Corresponding author: \\ Dr Mir Saaduddin Ahmad \\ Director of Academic Medicine, \\ Level 4, Dr Nizam Medical Centre \\ House A151, Road 4 \\ Niketan, Gulshan 1 \\ Dhaka-1212, \\ Bangladesh \\ dr.msahmad@gmail.com
}

Mir Saaduddin Ahmad is the Training Programme Director for the Postgraduate Fellowship in Migrant and Refugee Health that is run in Cox's Bazar by Doctors Worldwide.

Kay Mohanna is Professor of Values Based Health Professions Education at Worcester University and has deployed to Cox's Bazar as expert faculty for the Doctors Worldwide PGF programme.

\section{Acknowledgments:}

The authors would like to acknowledge the Doctors Worldwide Postgraduate Fellowship project team for their efforts in bringing the programme to fruition - Monowara Gani, Georgia Venner, Najeeb Rahman and Sayeed Ahmed.

The PGF and associated activities are funded by both Doctors Worldwide and the International Organisation for Migration (IOM) and is free to participants. Faculty donate their time for free and receive travel and other expenses. 


\title{
Establishing a postgraduate fellowship in humanitarian medicine - building capacity and ensuring sustainability for the health sector in the Rohingya Crisis
}

\begin{abstract}
The Postgraduate Fellowship for Migrant and Refugee Health (PGF) is a 13week programme of training, mentorship and workplace-based assessment for junior doctors working in the Rohingya migrant camps of Bangladesh. To date, four cohorts of 25 doctors who work in Primary Health Centres run by NonGovernmental Organisations (NGOs) have completed the programme. The PGF was developed and delivered by Doctors Worldwide (DWW), a UK-based international charity which aims to improve the health of communities by working in partnership with international, national and grassroots organisations focusing on health access, health improvement and health emergencies. The doctors working in the camps carry a burden of responsibility often out of proportion to their training, experience and seniority. The isolated nature of the camp health facilities, the paucity of equipment, drugs and facilities and the lack of any senior mentorship mean that clinicians have had to learn new roles and responsibilities on the job. Doctors Worldwide recognised this unique challenge at the start of the crisis in the latter half of 2017 and since 2018 it has successfully run the PGF using an international community of content developers with travelling and local teaching and support.
\end{abstract}

Keywords: refugee health; postgraduate training; workplace-based assessment; communities of practice

\section{Background}

As with many such crises, the forced displacement of Myanmar nationals belonging to the Rakhine state occurred in a part of the world that was not ready to receive an influx of such a large scale. The southeast coastal belt of Bangladesh is known for its natural beauty and nature reserve but does not have the infrastructure to cope with approximately 885,000 Rohingya refugees now residing in Cox's Bazar district [1]. The Rohingya community is acknowledged to have already been disadvantaged at home 
within Myanmar with very low levels of formal education, low socio-economic status and possible high levels of unmet health needs [2]. This level of need would be a challenge for even the most developed of nations. The Bangladeshi government and the international community have demonstrated a strong humanitarian commitment and since the latest outbreak of violence in August 2017, a total of nearly USD 2.8 billion has been provided to the Rohingya crisis response. This is in addition to USD 700 million in development commitments to Bangladesh from the World Bank and Asian Development Bank. However, many sectors, including Health, have had to depend on local human resources with little or no experience in humanitarian care.

The initial humanitarian development followed the WHO Health Cluster approach [2] "to relieve suffering and save lives in humanitarian emergencies, while advancing the well-being and dignity of affected populations". This created a foundation of 'Level one' primary care centres to cater to all the primary care needs of both the host and migrant communities, and additionally provide emergency care, maternal care and admission for observations. These now feed into new and existing secondary and tertiary care facilities regionally and even nationally.

The majority of doctors running these centres are within five years of graduation. They were recruited locally by NGOs and have stayed on with periodical renewal of contracts and intermittent deployment of expatriate colleagues. Career progression is uncertain and continuing medical education is sporadic and reactive. When Doctors Worldwide first arrived in November 2017 to carry out a needs assessment, it was clear that the gap did not lie in the number of clinicians on the ground, but rather in the skill set and experience of the practitioners who responded to the crisis out of a sense of altruism and motivated by social justice, but who had never faced the likes of the current challenge. With a focus on building capacity and providing 
sustainable healthcare and education that could be self-perpetuating without the need for external assistance, the PGF aimed to introduce new modalities of medical education following an adult learning, self-directed model. Much of this was a new approach for a cohort of doctors who had thus far received didactic lectures in medical school and the occasional workshops as set up by the Health Cluster. These latter were important sources of information about provision of facilities and protocol-driven care but were designed to hand over knowledge, rather than facilitate growth in learning and develop a cadre of doctors who could identify and address their own future learning needs.

\section{Programme Development}

To gain the maximum impact from the limited amount of field time available, a community of practice approach was developed [3]. This allowed experienced DWW expatriate faculty to share their knowledge and skills with local participants while simultaneously mentoring them on an individual basis.

The domain of practice, after Wenger [3], was defined by DWW as the primary healthcare facilities within the extended migrant camps. These included stand-alone health posts (sometimes just a chair, a table and a single doctor harboured under a shelter) to the more comprehensive primary healthcare centres (open twenty-four hours a day, seven days a week). The community identified were doctors working at these facilities who registered for the free training programme on their one free day per week, after approval of their line-managers. It also included a selected group of local and expatriate specialists intermittently deployed to the camps (26 UK based colleagues) as well as a team of over 50 specialist content developers from 6 countries, who engaged remotely. The practice seeking to be improved was the wide range of primary care interventions that this unique group of healthcare users accessed at these facilities. 
A pilot programme was run over a period of three weeks in February 2018 to engage with the learners and carry out a feasibility study. During this period, learning needs were identified and content or activities were identified to match (Table 1). Different modalities of learning (Figure 1) were put forward to enhance the learner experience and the need to provide mentorship and direct clinical supervision was recognised in order to provide immediate solutions for the clinical problems encountered. A deliberate effort was made to introduce a variety of supported, active learning methods to scaffold learners from a dependence on familiar content-rich lectures to a more self-directed, process-rich style of learning.

Principles of reflective practice as a way of identifying blind spots in knowledge and practice were introduced and elements of mentoring from the community (visitors and other participants) were integrated to facilitate a sustainable learning experience. Each participant had a logbook to record mini-clinical evaluation exercises and direct observations of procedures and faculty were deployed into the camps to sit alongside and engage in professional conversations in real-time with the participants. In addition, the logbook enabled reflection on clinical decision making to be facilitated back in the classroom using case-based discussions. Despite the often chaotic and always busy clinical environment, once the benefits of enhanced professional practice were noted by participants, and the non-judgmental approach of the visiting faculty was experienced, this novel form of learning was valued. Importantly, it was reassuring that local Community Health Workers drawn from the Rohingya community confirmed that such third-party presence from faculty in the consultation was largely acceptable to patients. The programme ran for 13 weeks and was repeated four times during a two-year period. The programme duration was short enough to avoid drop-out due to change in circumstances of the participants, but long enough to allow community learning to 
develop, both on the part of the participants and faculty. For the faculty and the programme, each cohort improved upon the previous by means of a rigorous system of monitoring, evaluation, assessment and learning exercises. This included the review of field data and practices as well as live feedback from participants and their line managers.

\section{Outcomes}

The development of a community of practice for the participants was a rewarding outcome and this developed organically. Previously participants had been in the bubble of their own organisations, unaware of the array of resources at hand. Through the PGF, not only were they able to learn clinical skills from each other but they were able to link up with one another and establish best practices in the absence of formal guidelines. The community also developed conventionally in the sense that bonds were formed and previous cohorts were looked upon as older and wiser siblings. Following up with the PGF participants a year after the last cohort reveals that the camaraderie is still strong and many of the PGF alumni have moved up the career pathways and are guiding their younger colleagues well (Table 2). The majority of the participants entered into the PGF programme when they were at the entry level grade of Medical Officer (equivalent to an intern, house officer or foundation doctor) within their parent organisations. Many now have been appointed to supervisory and coordination roles or have moved on to larger, international organisations.

A total of 787 hours of clinical shadowing were conducted in addition to the 423 hours of classroom training. Over 1500 workplace-based assessments were recorded and reviewed by the 26 expert faculty. The 99 medical doctors trained over the four cohorts received an additional 602 professional certificates from third-party online courses that were facilitated through the PGF programme. 
In the project's final impact review, participants reported an increase in confidence in patient management. They felt that the overall care extended to patients had improved through their own exposure to international standards of medical care. Most importantly, they felt empowered to demonstrate their leadership abilities, for example by introducing elements from the teaching such as the practice of triage in their own organisations. A participant from the third cohort of training in 2019 stated the following:

'I came across a patient who was not breathing. I performed the head tilt and chin lift procedure that I was taught in one of the PGF simulation sessions. I was able to help the patient breathe again. I felt so happy.'

Patient satisfaction with the care provided has been a challenge to evaluate due to language and logistical difficulties but is ongoing and will be reported elsewhere.

\section{Discussion}

Wenger suggests that three 'modes of belonging' are important aspects of learning in communities of practice: engagement, alignment and imagination. These act to:

'anchor [learning] in practice, yet make it broad, creative and effective in the wider world'.

Reflective practice, such as integrated into the PGF, results from the effective combination of engagement plus imagination. Wenger points out that the presence of an outside view, such as provided by the PGF mentors, enables participants both to engage fully with the reality of their experience for example by have attention brought to unconscious aspects of practice, and also to trigger new interpretations enabling the imagination of other futures - where clinical practice might be enhanced. Imagination must be combined with alignment to context however, to ensure it is not just a fantasy, 
and this combination situates learning back in practice. Additionally, the learning that can result from combining alignment with imagination ensures that practitioners remain adaptable when situations change for example when protocols do not apply or resources do not allow a preferred course of action. Combining the modes of belonging of engagement plus alignment within a community of practice leads to professional conversations that can fully exploit variation in practice. In negotiating and defending our practice with colleagues, we can come to see ambiguities, inconsistencies and perhaps mutually develop new ways of doing things.

\section{Conclusion}

Through a process of professional engagement with colleagues, catalysed by the PGF, a creative community of practice has developed. This model of teaching, although resource intensive at its initiation, has led to a vibrant, self-sustaining community of practice among the doctors of the Rohingya refugee camps. The PGF alumni are arranging in-house training of their own for their allied health professional colleagues, employing a number of the learning techniques from the PGF. Doctors Worldwide has further plans of running the PGF in 2021, not only for doctors, but for nurses, midwives and medical assistants, in parallel programmes.

\section{References:}

1. United Nations High Commission for Refugees (2020) www.unhcr.org/news/press/2020/10/5f915c464/conference-sustaining-supportrohingya-refugee-response-22-october-2020.html (accessed 30.10.20)

2. Mobarak, AM (2020) Socioeconomic Characteristics of Rohingya Refugees from Myanmar Living in Bangladesh; Yale Research Initiative on Innovation and Scale (Y-RISE); New Haven: Yale University Press. 
3. World Health Organisation (2020). Health Clusters in Countries https://www.who.int/health-cluster/countries/en (accessed 30.10.20)

4. Lave, J; Wenger, E (1991). Situated Learning: Legitimate Peripheral Participation. Cambridge: Cambridge University Press.

5. Wenger, E Communities of practice: Learning, Meaning and Identity (1998)

Cambridge: Cambridge University Press

Table 1. The PGF curriculum broken down into its 7 modules and corresponding units.

\begin{tabular}{|c|c|c|c|}
\hline $\begin{array}{l}\text { Module } \\
\text { Number }\end{array}$ & Module Title & $\begin{array}{c}\text { Unit } \\
\text { Numbe } \\
r \\
\end{array}$ & Unit Title \\
\hline \multirow{10}{*}{1} & \multirow{10}{*}{$\begin{array}{l}\text { Health in } \\
\text { Humanitarian } \\
\text { Emergencies }\end{array}$} & 1 & Introduction to humanitarian principles \\
\hline & & 2 & Historical, current and emerging trends in humanitarian action \\
\hline & & 3 & $\begin{array}{l}\text { Challenges of healthcare delivery in crisis situations - } \\
\text { contextualised focus }\end{array}$ \\
\hline & & 4 & The Cluster system and the Sphere Standards \\
\hline & & 5 & $\begin{array}{l}\text { Methodologies to identify health needs of populations in } \\
\text { humanitarian crisis }\end{array}$ \\
\hline & & 6 & Sector-specific health interventions in refugee camps \\
\hline & & 7 & $\begin{array}{l}\text { Cross-cutting health issues, i.e., disability, elderly, women and } \\
\text { children }\end{array}$ \\
\hline & & 8 & Ethical considerations \\
\hline & & 9 & The future of humanitarianism and innovations \\
\hline & & 10 & The written assessment \\
\hline \multirow{9}{*}{2} & \multirow{9}{*}{$\begin{array}{l}\text { Emergency Care } \\
\text { and Triage }\end{array}$} & 1 & Triage \\
\hline & & 2 & Airway and Breathing \\
\hline & & 3 & Circulation \\
\hline & & 4 & Disability and Exposure \\
\hline & & 5 & Head Injury \\
\hline & & 6 & Diarrhoea and Dehydration \\
\hline & & 7 & Special circumstances \\
\hline & & 8 & Malnutrition \\
\hline & & 9 & Implementing Triage Protocols \\
\hline \multirow{7}{*}{3} & \multirow{7}{*}{$\begin{array}{l}\text { Communicable } \\
\text { diseases in } \\
\text { Humanitarian } \\
\text { Crises }\end{array}$} & 1 & Understanding communicable disease risk assessments \\
\hline & & 2 & Surveillance and the role of early warning scores \\
\hline & & 3 & Vaccine-preventable diseases \\
\hline & & 4 & Meningitis and epidemic Meningitis \\
\hline & & 5 & Acute Respiratory Diseases \\
\hline & & 6 & Gastrointestinal infections \\
\hline & & 7 & Skin Infections and infestations \\
\hline
\end{tabular}




\begin{tabular}{|c|c|c|c|}
\hline & & 8 & Vector Borne diseases \\
\hline & & 9 & Sexually transmitted Infections \\
\hline & & 10 & High consequence infectious disease \\
\hline & & 11 & Outbreaks \\
\hline \multirow{9}{*}{4} & \multirow{9}{*}{$\begin{array}{l}\text { Non- } \\
\text { communicable } \\
\text { diseases and } \\
\text { Palliative care }\end{array}$} & 1 & Introduction to Non-communicable disease \\
\hline & & 2 & Challenges in Managing chronic disease \\
\hline & & 3 & Role of primary care facilities and preparedness \\
\hline & & 4 & Promoting health behaviours \\
\hline & & 5 & Cardiovascular disease and hypertension \\
\hline & & 6 & Diabetes \\
\hline & & 7 & Chronic Respiratory Diseases \\
\hline & & 8 & Cancer \\
\hline & & 9 & An approach to palliative care \\
\hline \multirow{8}{*}{5} & \multirow{8}{*}{$\begin{array}{l}\text { Mental health in } \\
\text { humanitarian } \\
\text { emergencies }\end{array}$} & 1 & Communication skills, assessment and management \\
\hline & & 2 & Reducing stress and strengthening social support \\
\hline & & 3 & Protection of human rights and holistic care \\
\hline & & 4 & Acute Stress, grief and post-traumatic stress disorder \\
\hline & & 5 & Moderate to severe depressive disorders and suicide \\
\hline & & 6 & Psychosis \\
\hline & & 7 & Epilepsy/Seizures and intellectual disability \\
\hline & & 8 & Harmful use of drugs and alcohol \\
\hline \multirow{8}{*}{6} & \multirow{8}{*}{$\begin{array}{l}\text { Maternal and } \\
\text { child health }\end{array}$} & 1 & Introduction to SRH in humanitarian settings \\
\hline & & 2 & Sexual and Gender-Based Violence \\
\hline & & 3 & SGBV Counselling \\
\hline & & 4 & Antenatal and postnatal care \\
\hline & & 5 & Obstetric emergencies \\
\hline & & 6 & New born Health \\
\hline & & 7 & Contraception and family planning \\
\hline & & 8 & Unsafe Abortion \\
\hline \multirow{8}{*}{7} & \multirow{8}{*}{$\begin{array}{l}\text { Professional and } \\
\text { communication } \\
\text { skills }\end{array}$} & 1 & Professional Standards and Ethics \\
\hline & & 2 & Consultation Models \\
\hline & & 3 & Communication Skills \\
\hline & & 4 & Focused patient assessment \\
\hline & & 5 & Medical record keeping and documentation \\
\hline & & 6 & Hygiene and infection control \\
\hline & & 7 & Good Prescribing Practice \\
\hline & & 8 & Public health considerations \\
\hline
\end{tabular}


Table 2. Examples of career progression of some PGF alumni. Although most of the participants had been working in the camps from the outset, it is interesting to see that the earlier cohorts have moved much further than the latter.

\begin{tabular}{|c|c|c|c|c|}
\hline $\begin{array}{c}\text { Alumni } \\
\text { no. }\end{array}$ & Gender & Post and organisation during PGF & $\begin{array}{l}\text { Training } \\
\text { Cohort }\end{array}$ & Present post and organisation \\
\hline 1 & M & $\begin{array}{l}\text { Assistant medical coordinator, Migrant } \\
\text { Offshore Aid Station (MOAS) }\end{array}$ & A & $\begin{array}{l}\text { Surveillance and immunisation officer, } \\
\text { World Health Organisation (WHO) } \\
\text { National team }\end{array}$ \\
\hline 2 & $\mathrm{~F}$ & $\begin{array}{l}\text { Medical officer, International } \\
\text { Organisation for Migration (IOM) }\end{array}$ & A & $\begin{array}{l}\text { Clinical supervisor and facility in charge, } \\
\text { IOM }\end{array}$ \\
\hline 3 & M & $\begin{array}{l}\text { Nutrition and Health Deputy Program } \\
\text { Manager, Nayapar stabilisation centre }\end{array}$ & A & Immunization and outbreaks officer, WHO \\
\hline 4 & M & $\begin{array}{l}\text { Consultant, Sexual and Reproductive } \\
\text { Health and Rights (SRHR), United } \\
\text { Nations Population Fund (UNFPA) }\end{array}$ & A & $\begin{array}{l}\text { National Quality Assurance Analyst, } \\
\text { UNFPA }\end{array}$ \\
\hline 5 & $\mathrm{~F}$ & Medical officer, IOM & A & National program officer, SRHR, IOM \\
\hline 6 & M & Medical officer, IOM & $\mathrm{B}$ & $\begin{array}{l}\text { Assistant surgeon, Ministry of Health and } \\
\text { Family welfare, Bangladesh Civil Service }\end{array}$ \\
\hline 7 & $\mathrm{~F}$ & Medical officer, We the dreamers & B & $\begin{array}{l}\text { Surveillance and Immunisation medical } \\
\text { officer, WHO }\end{array}$ \\
\hline 8 & M & Medical officer in charge, IOM & $\mathrm{B}$ & $\begin{array}{l}\text { Clinical supervisor for Health outreach } \\
\text { team and community based surveillance, } \\
\text { IOM }\end{array}$ \\
\hline 9 & $\mathrm{~F}$ & Medical officer, IOM & B & Medical officer, sonologist, UHC \\
\hline 10 & M & Facility in charge, IOM & $\mathrm{B}$ & $\begin{array}{l}\text { Medical officer, Paediatrics, Treatment } \\
\text { Medical Centre }\end{array}$ \\
\hline 11 & M & Clinical supervisor, Relief International & $\mathrm{B}$ & $\begin{array}{l}\text { Studying Masters in Public Health, } \\
\text { University of Eastern Finland }\end{array}$ \\
\hline 12 & $\mathrm{~F}$ & $\begin{array}{l}\text { Medical officer, Multiple facilities, } \\
\text { IOM }\end{array}$ & $\mathrm{C}$ & $\begin{array}{l}\text { Clinical supervisor, Camp 2W Infection } \\
\text { Treatment Centre (ITC), IOM }\end{array}$ \\
\hline 13 & M & Medical officer, IOM & $\mathrm{C}$ & $\begin{array}{l}\text { Clinical supervisor, Emergency } \\
\text { preparedness and response unit, IOM }\end{array}$ \\
\hline 14 & $\mathrm{~F}$ & $\begin{array}{l}\text { Senior RH Manager, } 19 \text { facilities, } \\
\text { International Rescue Committee (IRC) }\end{array}$ & $\mathrm{C}$ & Senior RH Manager, 28 facilities, IRC \\
\hline 15 & $\mathrm{~F}$ & Medical officer, IOM & $\mathrm{D}$ & Medical officer, IOM \\
\hline 16 & M & $\begin{array}{l}\text { Medical officer, Association for Socio- } \\
\text { Economic Advancement of Bangladesh } \\
\text { (ASEAB) }\end{array}$ & $\mathrm{D}$ & Medical officer, Kutupalong, IOM \\
\hline 17 & $\mathrm{~F}$ & $\begin{array}{l}\text { Clinical manager, Research Training } \\
\text { Management International (RTMI) }\end{array}$ & $\mathrm{D}$ & $\begin{array}{l}\text { Health field officer, International } \\
\text { Committee of the Red Cross (ICRC) }\end{array}$ \\
\hline 18 & $\mathrm{~F}$ & Medical officer, Inani sub centre & $\mathrm{D}$ & Medical officer, Inani sub centre \\
\hline
\end{tabular}


Figure 1. Modalities of learning used in the PGF matched to the cone of learning.

\section{The Doctors Worldwide Postgraduate Fellowship Cone of Learning}

\begin{tabular}{|c|c|c|}
\hline \multirow{3}{*}{$\begin{array}{c}90 \% \text { of what we say } \\
\text { and do }\end{array}$} & Doing the real thing & \multirow{5}{*}{$\begin{array}{l}\text { Clinical supervision } \\
\text { Simulation scenarios } \\
\text { Practical skills training } \\
\text { Directly observed skills } \\
\text { Table-top exercise } \\
\text { Focused group discussions } \\
\text { Case-based discussions } \\
\text { Reflective practice }\end{array}$} \\
\hline & Simulating the real experience & \\
\hline & Doing a dramatic presentation & \\
\hline \multirow{2}{*}{$70 \%$ of what we say } & Giving a talk & \\
\hline & Participating in a discussion & \\
\hline \multirow{2}{*}{$\begin{array}{c}50 \% \text { of what we hear } \\
\text { and see }\end{array}$} & Seeing it done on location & \multirow{5}{*}{$\begin{array}{l}\text { Role play } \\
\text { Multi-med } \\
\text { On-line cer } \\
\text { Handouts } \\
\text { Lectures }\end{array}$} \\
\hline & Watching a demonstration & \\
\hline \multicolumn{2}{|l|}{$30 \%$ of what we see } & \\
\hline \multicolumn{2}{|l|}{$20 \%$ of what we hear } & \\
\hline $10 \%$ of what we read & Reading & \\
\hline Retention Ability & Nature of Involvement & PGF Activity \\
\hline
\end{tabular}




\begin{tabular}{|c|c|c|c|}
\hline $\begin{array}{l}\text { Module } \\
\text { Number }\end{array}$ & Module Title & $\begin{array}{l}\text { Unit } \\
\text { Number }\end{array}$ & Unit Title \\
\hline \multirow{10}{*}{1} & \multirow{10}{*}{$\begin{array}{l}\text { Health in } \\
\text { Humanitarian } \\
\text { Emergencies }\end{array}$} & 1 & Introduction to humanitarian principles \\
\hline & & 2 & Historical, current and emerging trends in humanitarian action \\
\hline & & 3 & $\begin{array}{l}\text { Challenges of healthcare delivery in crisis situations - } \\
\text { contextualised focus }\end{array}$ \\
\hline & & 4 & The Cluster system and the Sphere Standards \\
\hline & & 5 & $\begin{array}{l}\text { Methodologies to identify health needs of populations in } \\
\text { humanitarian crisis }\end{array}$ \\
\hline & & 6 & Sector-specific health interventions in refugee camps \\
\hline & & 7 & $\begin{array}{l}\text { Cross-cutting health issues, i.e., disability, elderly, women and } \\
\text { children }\end{array}$ \\
\hline & & 8 & Ethical considerations \\
\hline & & 9 & The future of humanitarianism and innovations \\
\hline & & 10 & The written assessment \\
\hline \multirow{9}{*}{2} & \multirow{9}{*}{$\begin{array}{l}\text { Emergency Care } \\
\text { and Triage }\end{array}$} & 1 & Triage \\
\hline & & 2 & Airway and Breathing \\
\hline & & 3 & Circulation \\
\hline & & 4 & Disability and Exposure \\
\hline & & 5 & Head Injury \\
\hline & & 6 & Diarrhoea and Dehydration \\
\hline & & 7 & Special circumstances \\
\hline & & 8 & Malnutrition \\
\hline & & 9 & Implementing Triage Protocols \\
\hline \multirow{11}{*}{3} & \multirow{11}{*}{$\begin{array}{l}\text { Communicable } \\
\text { diseases in } \\
\text { Humanitarian } \\
\text { Crises }\end{array}$} & 1 & Understanding communicable disease risk assessments \\
\hline & & 2 & Surveillance and the role of early warning scores \\
\hline & & 3 & Vaccine-preventable diseases \\
\hline & & 4 & Meningitis and epidemic Meningitis \\
\hline & & 5 & Acute Respiratory Diseases \\
\hline & & 6 & Gastrointestinal infections \\
\hline & & 7 & Skin Infections and infestations \\
\hline & & 8 & Vector Borne diseases \\
\hline & & 9 & Sexually transmitted Infections \\
\hline & & 10 & High consequence infectious disease \\
\hline & & 11 & Outbreaks \\
\hline
\end{tabular}




\begin{tabular}{|c|c|c|c|}
\hline \multirow{9}{*}{4} & \multirow{9}{*}{$\begin{array}{l}\text { Non- } \\
\text { communicable } \\
\text { diseases and } \\
\text { Palliative care }\end{array}$} & 1 & Introduction to Non-communicable disease \\
\hline & & 2 & Challenges in Managing chronic disease \\
\hline & & 3 & Role of primary care facilities and preparedness \\
\hline & & 4 & Promoting health behaviours \\
\hline & & 5 & Cardiovascular disease and hypertension \\
\hline & & 6 & Diabetes \\
\hline & & 7 & Chronic Respiratory Diseases \\
\hline & & 8 & Cancer \\
\hline & & 9 & An approach to palliative care \\
\hline \multirow{8}{*}{5} & \multirow{8}{*}{$\begin{array}{l}\text { Mental health in } \\
\text { humanitarian } \\
\text { emergencies }\end{array}$} & 1 & Communication skills, assessment and management \\
\hline & & 2 & Reducing stress and strengthening social support \\
\hline & & 3 & Protection of human rights and holistic care \\
\hline & & 4 & Acute Stress, grief and post-traumatic stress disorder \\
\hline & & 5 & Moderate to severe depressive disorders and suicide \\
\hline & & 6 & Psychosis \\
\hline & & 7 & Epilepsy/Seizures and intellectual disability \\
\hline & & 8 & Harmful use of drugs and alcohol \\
\hline \multirow{8}{*}{6} & \multirow{8}{*}{$\begin{array}{l}\text { Maternal and } \\
\text { child health }\end{array}$} & 1 & Introduction to SRH in humanitarian settings \\
\hline & & 2 & Sexual and Gender-Based Violence \\
\hline & & 3 & SGBV Counselling \\
\hline & & 4 & Antenatal and postnatal care \\
\hline & & 5 & Obstetric emergencies \\
\hline & & 6 & New born Health \\
\hline & & 7 & Contraception and family planning \\
\hline & & 8 & Unsafe Abortion \\
\hline \multirow{8}{*}{7} & \multirow{8}{*}{$\begin{array}{l}\text { Professional and } \\
\text { communication } \\
\text { skills }\end{array}$} & 1 & Professional Standards and Ethics \\
\hline & & 2 & Consultation Models \\
\hline & & 3 & Communication Skills \\
\hline & & 4 & Focused patient assessment \\
\hline & & 5 & Medical record keeping and documentation \\
\hline & & 6 & Hygiene and infection control \\
\hline & & 7 & Good Prescribing Practice \\
\hline & & 8 & Public health considerations \\
\hline
\end{tabular}




\begin{tabular}{|c|c|c|c|c|}
\hline $\begin{array}{c}\text { Alumni } \\
\text { no. }\end{array}$ & Gender & Post and organisation during PGF & $\begin{array}{c}\text { Training } \\
\text { Cohort }\end{array}$ & Present post and organisation \\
\hline 1 & M & $\begin{array}{l}\text { Assistant medical coordinator, Migrant } \\
\text { Offshore Aid Station (MOAS) }\end{array}$ & A & $\begin{array}{l}\text { Surveillance and immunisation officer, } \\
\text { World Health Organisation (WHO) } \\
\text { National team }\end{array}$ \\
\hline 2 & $\mathrm{~F}$ & $\begin{array}{l}\text { Medical officer, International } \\
\text { Organisation for Migration (IOM) }\end{array}$ & A & $\begin{array}{l}\text { Clinical supervisor and facility in charge, } \\
\text { IOM }\end{array}$ \\
\hline 3 & M & $\begin{array}{l}\text { Nutrition and Health Deputy Program } \\
\text { Manager, Nayapar stabilisation centre }\end{array}$ & A & Immunization and outbreaks officer, WHO \\
\hline 4 & M & $\begin{array}{l}\text { Consultant, Sexual and Reproductive } \\
\text { Health and Rights (SRHR), United } \\
\text { Nations Population Fund (UNFPA) }\end{array}$ & A & $\begin{array}{l}\text { National Quality Assurance Analyst, } \\
\text { UNFPA }\end{array}$ \\
\hline 5 & $\mathrm{~F}$ & Medical officer, IOM & A & National program officer, SRHR, IOM \\
\hline 6 & M & Medical officer, IOM & $\mathrm{B}$ & $\begin{array}{l}\text { Assistant surgeon, Ministry of Health and } \\
\text { Family welfare, Bangladesh Civil Service }\end{array}$ \\
\hline 7 & $\mathrm{~F}$ & Medical officer, We the dreamers & $\mathrm{B}$ & $\begin{array}{l}\text { Surveillance and Immunisation medical } \\
\text { officer, WHO }\end{array}$ \\
\hline 8 & M & Medical officer in charge, IOM & $\mathrm{B}$ & $\begin{array}{l}\text { Clinical supervisor for Health outreach } \\
\text { team and community based surveillance, } \\
\text { IOM }\end{array}$ \\
\hline 9 & $\mathrm{~F}$ & Medical officer, IOM & B & Medical officer, sonologist, UHC \\
\hline 10 & M & Facility in charge, IOM & B & $\begin{array}{l}\text { Medical officer, Paediatrics, Treatment } \\
\text { Medical Centre }\end{array}$ \\
\hline 11 & M & Clinical supervisor, Relief International & B & $\begin{array}{l}\text { Studying Masters in Public Health, } \\
\text { University of Eastern Finland }\end{array}$ \\
\hline 12 & $\mathrm{~F}$ & $\begin{array}{l}\text { Medical officer, Multiple facilities, } \\
\text { IOM }\end{array}$ & $\mathrm{C}$ & $\begin{array}{l}\text { Clinical supervisor, Camp 2W Infection } \\
\text { Treatment Centre (ITC), IOM }\end{array}$ \\
\hline 13 & M & Medical officer, IOM & $\mathrm{C}$ & $\begin{array}{l}\text { Clinical supervisor, Emergency } \\
\text { preparedness and response unit, IOM }\end{array}$ \\
\hline 14 & $\mathrm{~F}$ & $\begin{array}{l}\text { Senior RH Manager, } 19 \text { facilities, } \\
\text { International Rescue Committee (IRC) }\end{array}$ & $\mathrm{C}$ & Senior RH Manager, 28 facilities, IRC \\
\hline 15 & $\mathrm{~F}$ & Medical officer, IOM & $\mathrm{D}$ & Medical officer, IOM \\
\hline 16 & M & $\begin{array}{l}\text { Medical officer, Association for Socio- } \\
\text { Economic Advancement of Bangladesh } \\
\text { (ASEAB) }\end{array}$ & $\mathrm{D}$ & Medical officer, Kutupalong, IOM \\
\hline 17 & $\mathrm{~F}$ & $\begin{array}{l}\text { Clinical manager, Research Training } \\
\text { Management International (RTMI) }\end{array}$ & $\mathrm{D}$ & $\begin{array}{l}\text { Health field officer, International } \\
\text { Committee of the Red Cross (ICRC) }\end{array}$ \\
\hline 18 & $\mathrm{~F}$ & Medical officer, Inani sub centre & $\mathrm{D}$ & Medical officer, Inani sub centre \\
\hline
\end{tabular}

